\title{
INFORMATION MANAGEMENT SYSTEMS FOR CULTURAL HERITAGE AND CONSERVATION OF WORLD HERITAGE SITES. THE SILK ROADS CASE STUDY
}

\author{
Ona VILEIKIS ${ }^{1}$, Mario SANTANA QUINTERO ${ }^{1}$, Koen VAN BALEN ${ }^{1}$, \\ Barbara DUMONT ${ }^{2}$, Vincent TIGNY ${ }^{2}$ \\ ${ }^{1}$ Raymond Lemaire International Centre for Conservation (RLICC), \\ Katholieke Universiteit Leuven (K.U.Leuven) \\ Kasteelpark Arenberg 1 - B 2431, 3001 Heverlee, Belgium. \\ ona.vileikis@asro.kuleuven.be \\ ${ }^{2} \mathrm{GIM}$ nv, \\ Researchpark Haasrode 1505, Interleuvenlaan 5, B 3001 Heverlee, Belgium.
}

Keywords: Documentation, World Heritage, Information Management Systems, Serial Nomination.

\begin{abstract}
This paper discusses the application of Information Management Systems (IMS) in cultural heritage. IMS offer a set of tools for understanding, inventorying and documenting national, regional and World Heritage properties. Information Management Systems can assist State Parties, stakeholders and heritage site managers involved in cultural heritage management and conservation by easily mining, sharing and exchanging information from multiple sources based on international standards. Moreover, they aim to record, manage, visualize, analyze and disseminate heritage information. In close collaboration with five Central Asian countries, namely, Turkmenistan, Kazakhstan, Kyrgyzstan, Uzbekistan and Tajikistan; a Belgian consortium headed by the Raymond Lemaire International Centre for Conservation (RLICC), K.U.Leuven is developing the Silk Roads Cultural Heritage Resource Information System (CHRIS). This Web-based Information Management System supports the preparation of the Central Asia Silk Roads serial and transnational nominations on the UNESCO World Heritage list. The project has been set up thanks to the financial support of the Belgian Federal Science Policy Office (BELSPO) and in collaboration with UNESCO World Heritage Centre in conjunction with the People's Republic of China and the Japanese Funds-in-Trust UNESCO project. It provides a holistic approach for the recording, documentation, protection and monitoring tasks as part of the management of these potential World Heritage Properties. The Silk Roads CHRIS is easily accessible to the general user, presented in a bilingual English and Russian frame and interoperable, i.e. open for other applications to connect to. In this way, all information for the nomination dossiers is easily verified regarding consistency and quality and ready for managing, periodic reporting and monitoring processes in the respect to the property listed. Finally, this study provides a general framework to establish the effectiveness and limits of the use of information systems for serial transnational nominations of World Heritage Properties and to demonstrate the potentials of an improved heritage documentation system.
\end{abstract}

\section{INTRODUCTION}

Serial transnational World Heritage nominations are an opportunity to reach a more balanced World Heritage List, supporting the underrepresented regions and fostering international research. However, these nominations as well as the risks affecting the integrity of the properties are becoming an increasingly complex challenge for the authorities managing heritage places at different scales. Therefore, the use of Information Management Systems (IMS) is an opportunity to elaborate an accurate and reliable nomination dossier and allow exchange among the State Parties involved. World Heritage properties are confronted to a number of threats due to e.g. tourism, development, deterioration processes and climate change. Adequate monitoring of management measures should be proposed and include tracking physical changes of the monuments, controlling visitors' carrying capacity, and clearly defining the boundaries and buffer zones among other activities. Several charters and international conventions such as the World Heritage Convention, the Venice Charter, the Burra Charter and many others aim to guide site managers and protect these sites. However, when looking at serial transnational nominations, the issues mentioned before become more 
complex and require better coordination and more collaboration among State Parties. Therefore, the different stakeholders involved in World Heritage nominations need to find a way to improve collaboration and better understand their heritage places by easily mining, sharing and exchanging information from multiple sources using common standards. Following UNESCO's recommendations [7] in the use of digital technology, the application of IMS in cultural heritage is a cost-effective tool to easily understand, store, share, manage and monitor serial transnational World Heritage nominations. An IMS is able to support these kinds of nominations in the conservation and monitoring processes by defining standards, storing large data volume and acting as a collaborative platform for the State Parties to share information and take informed decisions. The case study of the Silk Roads Cultural Heritage Resource Information Management System (CHRIS) will illustrate the implementation of IMS on the elaboration of World Heritage nomination dossiers.

\subsection{Serial transnational World Heritage nominations}

A major purpose of the World Heritage Convention is to foster international cooperation for the protection and management of the outstanding cultural and natural heritage sites. The concept of serial nominations is an innovative approach supporting this aim. Serial nominations are submitted as single properties with one Outstanding Universal Value, and their nomination, monitoring and management must be treated as such [1]. Within this category and looking forward to a more representative, balanced and credible World Heritage List, serial transnational nominations are an opportunity to encourage collaboration and exchange between State Parties. However, these nominations come together with more complex challenges specifically in the systematization and management of the information. UNESCO World Heritage Centre and ICOMOS (International Council of Monuments and Sites) have encouraged the State Parties to identify and nominate new and underrepresented categories of properties, such as cultural routes, settlements and cultural landscapes. Some successful serial transnational inscriptions in cultural heritage are the Frontiers of the Roman Empire, and the Belfries of Belgium and France. However, only two cultural routes, namely the Camino Real de San Agustin and the Route of Santiago de Compostela, are listed while no transnational route has yet been inscribed [2]. Therefore, current initiatives such as the Silk Roads serial transnational nominations are of great interest to the World Heritage community. On the one hand, serial nominations create the opportunity for single heritage sites otherwise not on the UNESCO list, to be proposed and protected under a larger framework. In the case of serial transnational nominations, the component parts are protected by a management system at an international level. These types of nominations not only link cultures, regions and communities but are also an instrument for sustainable development and tourism at transnational, national and regional scale. Moreover, these nominations bring diversity in models and management strategies for the conservation of the sites [3,4]. On the other hand, these large nominations entail significantly higher efforts than a single nomination and are more complex when it comes to operability and legal issues. First, the preparation of serial transnational World Heritage nomination dossiers requires more resources, guidance and active joint collaboration. Some problems and issues on the elaboration of these nomination dossiers identified and discussed during international meetings $[5,6]$ were that:

(1) large volume of baseline information is required;

(2) there is no specific system to support the elaboration of complex nomination dossiers;

(3) overlapping and duplicate data may be collected especially at a transnational level due to different documentation procedures, geographic references, standards in conservation strategies and national policies;

(4) there is a need for exchange and joint use of data;

(5) there is a need for decisions based on critical thinking and the latter should not be limited to decisions by authorities without sufficient access to the appropriate expertise;

(6) there is a lack of technical expertise e.g. GIS, documentation and recording techniques.

Moreover, in transnational nominations each state party presents differences regarding social, political and legal characteristics making the coordination of management systems more complex. Some solutions may vary from bilateral agreements to more elaborated management partnerships. A joint management system should be proposed with a shared vision for the protection of the OUV. However, although all the property is covered under one umbrella, the World Heritage Convention and other international policies, each component part should comprise a set of objectives to later measure the State of Conservation and changes over time [3,5].

\subsection{The role of Information Management Systems in Cultural Heritage}

Adequate design and implementation of Information Management Systems allow a cycle process supporting cultural heritage activities such as documentation, inventorying, management strategies, monitoring, and reporting. As it needs to be regularly updated, various stakeholders and the local community can be involved. Although IMS are an opportunity in cultural heritage, they should be adapted depending on the national legislation, regional policies, and the local needs. As required by the World Heritage Convention a digital repository is essential for the inclusion of the sites on the List. Moreover, in serial properties with such a large volume of information and number of stakeholders, heritage managers need a better understanding of the properties in order to take informed decisions. IMS aim to overcome the 
problems and issues on serial transnational nominations by (1) creating a common platform to receive unlimited amount of information with secure and restricted access through the use of user profiles and access rights management, (2) allowing an analysis and comparison of the heritage places being the base for e.g. prioritizing development interventions or planning, redefinition of uses of the properties, or their interpretation, and (3) presenting consistent and reliable information. Nevertheless, most of the systems fail because of lack of data or because the end-users are not involved during the development and interpretation process. Often a bottom-up approach is not considered. IMS need to be adapted to the current legal circumstances and way of carrying out data repositories in each country, in order to easily input the information in the system. Moreover, heritage managers should have prompt access to the information being them the ones bridging the decision makers with the local community in order to protect the integrity and authenticity of the sites. The appropriate use of IMS in cultural heritage will have a positive outcome in the way of inventorying and decision-making of large heritage places. Their functions and tools allow different levels of engagement and open the opportunity to shift from a top-down to a bottom-up approach. However, each system should be tailor-made according to its purposes and users requirements.

\section{THE SILK ROADS AND ITS NOMINATION}

Nowadays, the Silk Roads nomination, with around 35,000 km of major routes of dialogue and exchange connecting East and West [7], it involves 12 State Parties and comprises more than 160 heritage sites already listed on the Tentative List. As agreed on during the Second meeting of the Coordinating Committee on the Serial World Heritage Nomination of the Silk Roads in Ashgabat, Turkmenistan, 50 potential cultural corridors were identified by an ICOMOS Thematic Study as a potential collection of serial and serial transnational properties all together defining the Silk Roads nomination overarching framework. This new nomination strategy aims to foster inter-State cooperation; allowing State Parties to act in smaller "groups" more independently, and to propose more manageable properties to be nominated on the World Heritage List. However, despite of this new approach, the elaboration and documentation of these serial transnational nomination dossiers in Central Asia still poses a number of problems and issues:

(1) the large extent of the considered territory;

(2) some of the inventory systems, e.g. Monument Passport as developed and used in the Soviet times, are standardized but are only available in hard copies and not much information is digitized;

(3) decision-makers are hardly acquainted with digital technology;

(4) the lack of technical expertise in documentation and recording as well as monitoring of cultural heritage in all Central Asian countries except for Kazakhstan [8,9];

(5) transnational collaboration is clear on paper but not in practice;

(6) in some countries there is a lack of integrated management plans or systems and of conservation strategies [6,9].

In dealing with these issues, the use of digital technology is a recommended cost-effective tool for better understanding and protection of serial transnational World Heritage properties [10]. Information Management Systems (IMS) easily allow storing, managing, and monitoring the baseline information during the elaboration of the nomination dossiers as well as after the properties are listed. Moreover, IMS ensure data integrity and improve quality control. Within this framework, UNESCO World Heritage Centre has allocated resources for underrepresented categories of properties and geographical regions to be technically supported during the nomination procedures in order to both, ensure the balance and credibility of the World Heritage List, and avoid the resubmission of nominations with incomplete files [11]. The Silk Roads serial transnational World Heritage nomination initiative is one of them. For the first phase of the Silk Roads serial transnational World Heritage nomination, two priority cultural corridors in Central Asia and one in China were selected. To carry out this task, two projects will be working in conjunction, the Japanese Funds-in-Trust UNESCO project dealing with the support for documentation standards and procedures of the Silk Roads Serial and transnational World Heritage Nomination in Central Asia, and the Silk Roads Cultural Heritage Resources Information System (CHRIS) project. The Silk Roads CHRIS project is an UNESCO WHC initiative funded by the Belgian Federal Science Policy Office (BELSPO) and executed by a Belgian consortium headed by the Raymond Lemaire International Centre for Conservation at the K.U.Leuven supporting the Silk Roads serial transnational World Heritage nomination of the five Central Asian countries, namely, the Republics of Kazakhstan, Kyrgyzstan, Tajikistan, Turkmenistan and Uzbekistan. It aims to overcome the nomination issues based on the Central Asian user requirements by: (1) improving and automatizing the documentation processes, (2) cross-referencing data at national and transnational level with international standards, (3) developing and implementing an effective web-based license free multilingual platform for information recording and sharing, (4) developing participatory editing tools with protected access rights, and (5) focusing on a thin-client approach for which no additional plug-ins are needed. Moreover, this user-friendly system will not require long trainings or specific qualifications for its use. The first demonstrator will be presented at the first documentation training in Uzbekistan to be evaluated by the Central Asian users in September 2011. 


\section{THE SILK ROADS CHRIS APPROACH}

The Silk Roads CHRIS is a web-based collaborative platform in development that is user-oriented and based on the Operational Guidelines on the World Heritage Convention [1] and the approach of the UNESCO Chair in Preventive Conservation, Maintenance and Monitoring of the Monuments and Sites (PRECOMOS) [12]. The system is accessible through standard Internet web browser allowing the implementation of a large number of actions and tools. It is based on "GIM Geo CMS" which is a combination of a Content Management System with a WebGIS application; and will be an evolution of the HERITECH IMS developed by GIM for the heritage managers of the City of Biograd na Moru in Croatia thanks to the support of the Flemish Government. This system shares the concepts of the Calakmul 4DGIS [13] developed in collaboration with UNESCO and with the financial support of BELSPO but is based on leading-edge technology. The Silk Roads CHRIS uses the geographical location of features of interest as common denominator for all the information stored in the system. This means that the user can navigate in the territory and interactively select (on the map or via a query) an heritage feature being represented as a point or as a detailed polygon in order to get linked information (textual description, associated pictures, documents, 3D models, videos, etc) illustrating the OUV of the property. Users with the required privileges can also edit and modify the information on line. Tailored maps can also be generated by overlaying a selection of available layers and then exported in usual formats to illustrate the nomination dossier. Finally the temporal dimension is also integrated and provides for additional monitoring and analysis capabilities. All this information comes together with metadata compliant with international standards such as ISO or Dublin Core. The information structure will be based on the current inventory system of the Central Asian monument passport and the variety of typologies identified in the region. In addition, the information is structured in a way that users, as a function of the groups to which they belong, will only have access to a set of counters providing for a set of relevant data layers and tools. Each counter focus on a specific purpose and the system offer full flexibility regarding the number of counters and functionalities available within each of them. Initially the Silk Roads CHRIS will provide a bilingual English-Russian integrated framework. The current methodology proposed by PRECOMOS is the application of Preventive Conservation to Cultural Heritage [14]. Preventive Conservation aims to avoid or mitigate the damages, understand the risks, and help to dilute responsibility. It also promotes maintenance as a preservation strategy based on proper monitoring. Figure 1 depicts the four phases of this process. Each one of them corresponds respectively to (1) search for significant or baseline information, (2) identification of missing information (3) choice of measures and answers to be taken, and (4) control of the efficiency of the actions or mitigations proposed. This approach includes systematic monitoring and maintenance supporting the conservation planning by looking back over and over again.

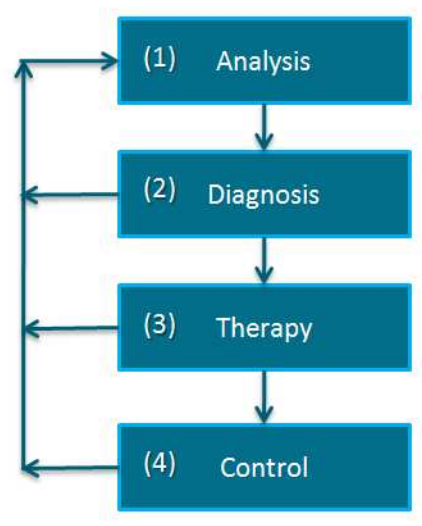

Figure 1: Scheme ICOMOS Charter - Principles for the Analysis, Conservation and Structural restoration of Architectural Heritage [14].

The concept previously introduced is integrated in the three major components of every information system, namely, data input, data processing and data output in order to better monitor and manage the property after it has been listed.

Figure 2 illustrates this result as it is proposed for the Silk Roads CHRIS approach. Afterwards these three features will be explained. First, the data input is the result of the analysis correlated with the different detailed and spatial scales. In the case of the Silk Roads, the analysis includes the baseline information requested for the nomination by the Operational Guidelines, e.g. geographical coordinates, historical background, risks and threats [1], the user requirements of the five Central Asian State Parties and the outcome of the State Parties interaction in the system as a transnational group. After having populated the system with data required for the nomination dossier, the State Parties can interact, e.g. they can define and adapt the buffer zone of the suggested corridor, and add or delete proposed component parts together with the associated information. All this information is visualized on top of background satellite images together with interpretation of processed images in GIS as geographical baseline documentation. 
However, if no satellite images are available other image sources will be used such as orthophotos at a large scale. Moreover, the system will focus on three spatial scales for the geospatial information to be included: the (1) Silk Roads (scale 1:400.000/ 1:600.000), the (2) corridors (scale 1:100.000/1:200.000) and the (3) component parts (scale 1:10.000/1:20.000) while offering unlimited in and out zooming capabilities. Furthermore, for the elaboration of nomination dossiers the baseline information can be obtained at a reconnaissance scale of heritage documentation. This scale allows a rapid assessment of the heritage place and its setting, giving an overview and understanding of the characteristics of the property and its component parts, identifying its significant elements, risks and management issues [15]. However, in order to effectively monitor and manage the property more detailed levels of documentation should be provided. Second, the data process includes both the (2) diagnosis and the answer to the diagnosis, meaning reviewing the information included in the system and reporting what kind of information is missing, and (3) giving a therapy or mitigation to these issues, e.g. what would be the next step to follow, either go back and look for more information or be ready and move forward to the Output Data. Finally, the data output is the result when the information is ready to be used for the nomination dossier and the diagnosis is positive. Here, (4) control or monitoring procedures will be applied after the property is listed to assist the Periodic Reporting.
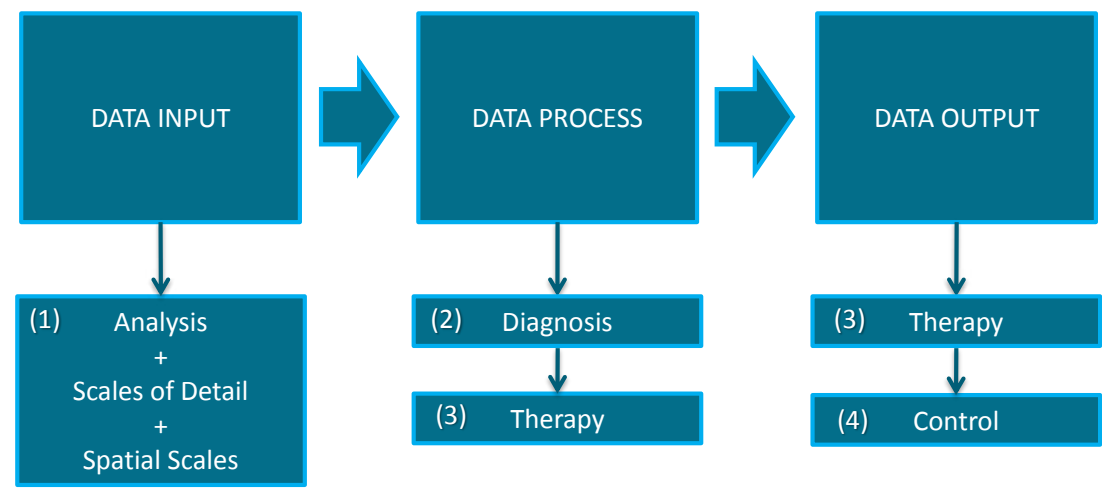

Figure 2: Approach of the Silk Roads CHRIS

\section{OUTCOMES}

Silk Roads CHRIS, although still in its early stages, is an opportunity for the Central Asian State Parties to virtually exchange and work together on the serial World Heritage nominations, overcoming physical boundaries. This flexible Information Management System will be able to hold texts, images, and 3D models moving from paper-based inventories to automated processes ensuring consistency of information, same structure for the submission on the World Heritage List as well as for the evaluation of the advisory bodies, the SoC and Periodic Reporting. Moreover, working together with the World Heritage Centre, the possibility to dynamically link the WHC database storing the data of the Tentative List with the Silk Roads CHRIS through the use of Open Archives Initiative - Protocol for Metadata Harvesting (OAI-PMH) is explored. However, some of the issues to overcome will be the different geographic projects and how to control quality and relevance of the information uploaded to the system.

\section{CONCLUSION}

Serial transnational World Heritage nominations are complex initiatives that have international attention as they contribute to the core objective of the Convention by promoting international collaboration. Their efficient documentation, management and monitoring are a vast challenge for the State Parties and stakeholders involved. The large volume of information involved requires better and more effective inventorying and sharing systems being in digital technology IMS as optimal tools to collect and process this data. The Silk Roads Cultural Heritage Resource Information System (CHRIS) is being developed as a flexible collaborative platform supporting the interaction of several State Parties aiming to elaborate nomination dossiers. With minor adaptations it could also be used for other serial transnational World Heritage nominations of this kind. Even if the use of the system does not guarantee the inclusion of the property on the World Heritage List it is undoubtedly an asset as it demonstrates management capabilities. Its main aim is to assist the preparation of the nomination dossier and later monitoring of properties and managing and updating of this information, by offering a common virtual space to the State Parties involved to cooperate and work together and developing standardized baseline data. In a second phase, the Silk Roads CHRIS will develop heritage tools for the monitoring and management of the properties after the property is listed. As the IMS is a flexible and unlimited tool new applications such as the use of a timeline and the reporting and evaluation processes should be further explored. 


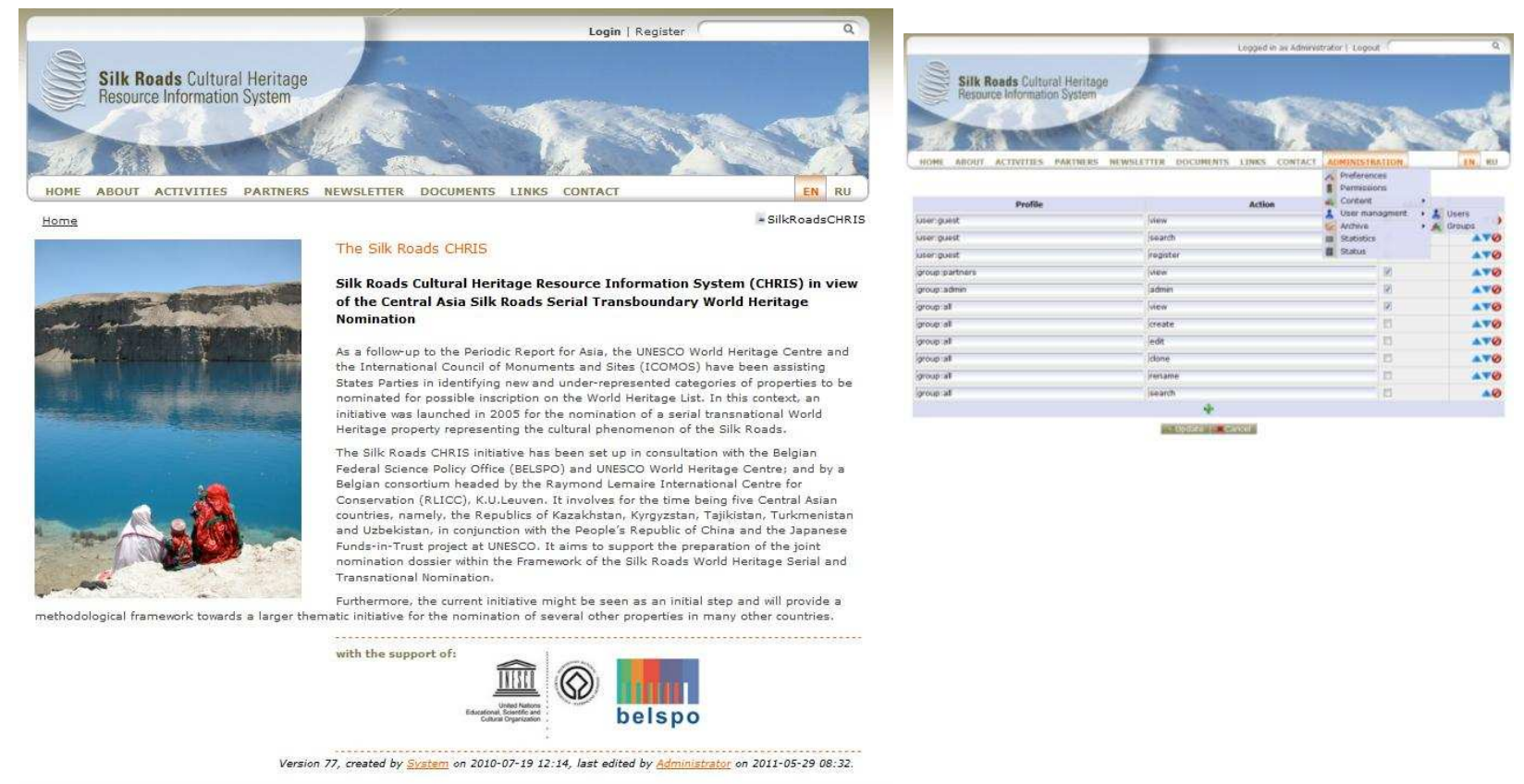

Figure 3: Silk Roads CHRIS Information Management System. Powered by GIM. http://www.silkroad-infosystem.org [Copyright: Silk Roads CHRIS Project]

\section{REFERENCES}

[1] UNESCO, Operational Guidelines for the Implementation of the World Heritage Convention. UN Doc WHC. 08/01 January 2008. 2008.

[2] UNESCO World Heritage Centre, World Heritage Centre - World Heritage List. [Online]. Available: http://whc.unesco.org/en/list. [Accessed: 11-Mar-2011].

[3] IUCN, Engels B., Koch P., and Badman T., Serial natural World Heritage properties. An initial analysis of the serial natural properties on the World Heritage List IUCN .

[4] B. Engels, Serial Natural Heritage Sites: A Model to Enhance Diversity of World Heritage?, in World Heritage and Cultural Diversity, vol. 4, Cottbus: German Commission for UNESCO, 2010, pp. 79-84.

[5] Swiss Federal Office of Culture, O. Martin, and S. Gendre, Eds., UNESCO World Heritage: Serial Properties and Nominations. Swiss Federal Office of Culture, 2010.

[6] Magin C., World Heritage Thematic Study for Central Asia a Regional Overview. 2005.

[7] Jing F., UNESCO's efforts in identifying the world heritage significance of the Silk Road, in Proceedings of the ICOMOS 15th General Assembly and Scientific Symposium. Xi'an, 2005, vol. 2, pp. 934-944.

[8] Fodde E., Conserving sites on the Central Asian Silk Roads: the case of Otrar Tobe, Kazakhstan, Conservation and management of archaeological sites, vol. 8, no. 2, p. 77, 2006.

[9] Fodde E., Conservation and conflict in the Central Asian Silk Roads. Journal of architectural conservation, vol. 16, no. 1 , p. $75,2010$.

[10] UNESCO, Guidelines for the Preparation of Serial Nominations to the World Heritage List. n.d.

[11] Cleere H., Denyer S., and Petzet M., The World heritage list : filling the gaps, an action plan for the future. Paris: ICOMOS, 2005.

[12] RLICC, Precomos - Preventive Conservation, Maintenance and Monitoring of Monuments and Sites [Online]. Available: http://precomos.org/index.php/member/login/. [Accessed: 07-Jun-2011].

[13] van Ruymbeke M., Tigny V., De Badts E., Garcia-Moreno R., and Billen R., Development and use of a 4D GIS to support the conservation of the Calakmul site (Mexico, World Heritage Programme), in Proceedings of the 14th International Conference on Virtual Systems and Multimedia, Limassol, Cyprus, 2008.

[14] ICOMOS, ICOMOS Charter- Principles for the Analysis, Conservation and Structural Restoration of Architectural Heritage. ICOMOS, 2003.

[15] Letellier R., Ed., Recording, Documentation, and Information Management for the Conservation of Heritage Places, The Getty Conservation Institute. Los Angeles: J. Paul Getty Trust, 2007. 